\title{
A literatura de viagem e a representação do Brasil por estrangeiros no século XIX
}

\author{
Patrícia Vargas Lopes de Araujo*
}

\begin{abstract}
RESUMO
Os "viajantes estrangeiros" foram extremamente importantes na elaboração de representações sobre o Brasil e contribuíram para a fixação de imagens sobre a sociedade brasileira. Diferentemente dos séculos anteriores, o século XIX conhecerá um grande afluxo de estrangeiros para terras brasileiras. A expansão mercantilista dos países europeus, a importância dada ao conhecimento das ciências e o interesse por outras culturas motivaram inúmeras viagens pelo mundo. Esses estrangeiros se dirigiam ao Brasil com finalidades diversas, como, por exemplo, fazer negócios, abrir casas comerciais, explorar riquezas, conhecer o país. A imagem que elaboraram sobre o Brasil, sua população e natureza se constituiu pautada pela cultura letrada europeia, considerada civilizada. E dessa maneira seriam portadores de uma série de estereótipos sobre o Brasil. Pretendemos com essa análise refletir sobre as temáticas da paisagem e da natureza a partir das obras (pinturas e relatos) produzidas por estrangeiros durante suas viagens ao Brasil durante o século XIX, dando-se destaque a Jean-Baptiste Debret e Johann Moritz Rugendas. Procuramos, nesse sentido, compreender o papel ou importância dos viajantes face à elaboração e à difusão de representações sobre Brasil.
\end{abstract}

Palavras-chave: Viajantes estrangeiros. Relatos de viagem. Paisagem. Natureza.

\section{The travel literature and the representation of Brazil by foreigners in the Nineteenth century}

\begin{abstract}
The "foreign travelers" were extremely important in the elaboration of representations about Brazil and contributed to the fixation of images on the Brazilian society. Unlike the previous centuries, the nineteenth century will experience a large influx of foreigners into Brazilian lands. The mercantilist expansion of the European countries, the importance given to the knowledge of the sciences and the interest in other cultures had motivated numerous trips around the world. These foreigners went to Brazil with several purposes, such as doing business, opening commercial houses, exploring riches, getting to know the country. The image they drew about Brazil, its population and its nature was based on the European literate culture, considered civilized. And in this way they would carry a series of stereotypes about Brazil. We intend with this analysis to reflect on the themes of the landscape and nature from the works (paintings and reports) produced by foreigners during their travels to Brazil in the 19th century, with a special mention to Jean-Baptiste Debret and Johann Moritz Rugendas. In this sense, we seek to

\footnotetext{
* Doutora em História pela Unicamp, com pós-doutorado em História do Urbanismo pela Escola de Arquitetura e Urbanismo da UFMG. Professora do Departamento de História da Universidade Federal de Viçosa (UFV) e do Mestrado Profissional em Patrimônio Cultural, Paisagens e Cidadania, integrando a Linha de Pesquisa Cidade, Paisagem e Patrimônio. E-mail: pvargasaraujo@hotmail.com. Este artigo é resultado do Projeto de Pesquisa "Nós e os Outros - Representações do Brasil através do olhar estrangeiro entre os séculos XVIII e XIX", PIBIC/CNPq 2017-2018. Agradecimentos ao bolsista de iniciação científica Rubens Albano Verona.
} 
understand the role or the importance of travelers in the elaboration and diffusion of representations about Brazil.

Keywords: Foreign travelers. Travel reports. Landscape. Nature.

Artigo recebido em 31 jan. 2019

Artigo aprovado em 09 mai. 2019

Certamente os chamados "viajantes estrangeiros" foram extremamente importantes na elaboração da ideia de Brasil na Europa e contribuíram, sobretudo, na elaboração e na fixação de imagens sobre a sociedade brasileira. Estes "viajantes" têm sido, desta maneira, convocados a dar conta, com seus depoimentos, relatos e pinturas, de uma parte significativa de nosso passado. Parte expressiva das representações sobre o Brasil, particularmente no século XIX, foram produzidas no contexto de viagens, por autores que tomavam como seu objetivo construir relatos capazes de transmitir a outrem as experiências vividas em terras pouco acessíveis e ainda desconhecidas (Leite, 1996, p. 38).

No caso do Brasil, os olhares dos viajantes revelam, em textos de línguas e de sensibilidades distintas, como também de épocas diferentes, certas permanências. Elementos de teor idílico, como formosura e fertilidade da terra, aspecto e afabilidade da população, como também questões relacionadas à novidade e à estranheza dos costumes, à religiosidade e à expectativa com a economia, estão presentes nos primeiros escritos do século XVI, como por exemplo em "A carta de Pero Vaz de Caminha" e em cronistas dos séculos seguintes. Mas é preciso notar as diferenças entre as primeiras narrativas de cunho edênico $e$ as visões marcadas pelo racionalismo e pelo empirismo dos viajantes que se aventurariam nas "viagens pitorescas" pelo interior do Brasil. O discurso do viajante do século XVI será marcado por referenciais renascentistas, no qual se pode perceber o esforço de estruturação de uma "História Natural", a apreensão de imagens e o estabelecimento de relações de semelhança e de contiguidade entre estas fundamentadas por analogias e aproximações.

Durante o período colonial, a produção literária construiu representações relativas aos nativos, às riquezas naturais e às terras, destacando-se, deste modo, um conjunto de imagens remetidas a um conteúdo vinculado à visão colonialista e etnocêntrica. Este período caracterizase por um pequeno número de estudos e pesquisas acerca do Brasil. A política exclusivista adotada por Portugal foi responsável, por exemplo, no final do século XVIII, pela expulsão do cientista alemão Alexander von Humboldt, cuja expedição seria considerada suspeita $e$ prejudicial aos interesses políticos do Reino (Leite, 1996, p. 41). Entre o século XVI até o início 
do século XIX, as explorações científicas, quando haviam, foram motivadas por disputas em torno da posse e da ocupação da terra. Tais expedições voltavam-se à investigação das riquezas naturais, que revelavam, portanto, a preocupação com a exploração do território.

Após a transferência da Corte Portuguesa para o Brasil e a abertura dos portos, diferente dos séculos anteriores, o século XIX conheceria um grande afluxo de estrangeiros para terras brasileiras. A expansão mercantilista de países europeus e dos Estados Unidos, a importância dada ao conhecimento das ciências e o interesse por outras culturas motivou inúmeras viagens pelo mundo.

O culto "ao outro" exercia grande fascínio entre os intelectuais europeus e os "países exóticos, como eram então chamadas às colônias, exerciam uma enorme atração" (Leite, 1997, p. 09). O Brasil era como muitas outras colônias e países procurados por colocar em questão o estranhamento e o "desconhecido" perante o viajante. Os temas relatados tiveram frequentemente como critérios de escolha, fatos considerados "exóticos". Sempre que possível eles procuraram evidenciar as diferenças entre seus países de origem e o Brasil.

Desta maneira, é fácil perceber que as relações estabelecidas entre viajantes e brasileiros, e o que estava por ser desvendado, eram desiguais. $\mathrm{Na}$ "qualidade de estrangeiro", esse viajante transformava-se em observador privilegiado e atento aos "aspectos, incoerências e contradições da vida cotidiana que os habitantes, ao dá-la como natural e permanente, encontravam-se incapazes de perceber" (Leite, 1996, p. 60). Por outro lado, o viajante chegava ao Brasil portando muitos preconceitos, munido da ideia de ser o modelo de "civilização" diante de um "povo atrasado". Tal postura agravava-se quando se viam frente a obstáculos linguísticos, culturais e econômicos. Na tentativa de compreensão dos grupos visitados, foram responsáveis por estereótipos que vigoraram por todo o século XIX.

A utilização dos relatos destes "estrangeiros" não deve perder de vista que seus registros são portadores de valores, preconceitos, assim como de uma visão idealizada sobre os trópicos, muitas vezes diferentes da realidade a ser explorada. É necessário "desconfiar das pistas viciadas que esses viajantes possam ter deixado" (Schwarcz, 1999, p. 12), mas se a incompreensão e o estranhamento diante de uma cultura diversa da sua os fizeram descaracterizar em muitas situações os costumes brasileiros, tornaram-lhes, por outro lado, extremamente detalhistas em suas descrições, fazendo de seus relatos preciosa fonte de informação. Mas, ainda assim, são necessários certos cuidados, pois os mesmos aspectos que fazem de seus relatos alternativas documentais interessantes, apresentam também seus limites. Dessa forma, a busca por sinais de alteridade faz com que a princípio, por desconhecimento da outra cultura, o viajante interprete mal as mensagens e os símbolos que recebe e lhes atribua outros sentidos e significados. 
Quanto à imagem do Brasil, continuava a se apresentar ao exterior uma ideia de "terra encantada", portadora de riquezas naturais, com belo clima, rios, flores e animais, e também a "decepção" com o atraso e o progresso. Deste modo, o índio e a natureza constituíam o foco principal das atenções. Agora, entretanto, fazendo parte de estudos sistemáticos e classificatórios. A ideia de progresso tão presente na Europa, reforçava sua a imagem como espaço de civilização e em contrapartida deformava o Outro pela comparação (Leite, 1996, p. 48).

A apreensão intelectual do Brasil e a construção de uma narrativa sobre sua história estavam vinculadas à aproximação ou distanciamento da natureza ou da civilização. A natureza permeou todas as concepções de América e de Brasil desde o século XVI, adquirindo grande relevância para pensar sua representação e sua incorporação ao conhecimento da época.

Nota-se nestas representações que o caráter positivo da natureza tropical se consolida, tornando-se uma imagem poderosa, a de uma natureza excessiva e provedora, junto a qual o homem se perderia, tornando-se pequeno e impotente. A natureza é tomada como objeto para a pesquisa científica e como inspiração artística, provocando sensações e ações tanto positivas quanto negativas, confortantes ou não, para aqueles que a observam.

Embora sejam objetos de estudos diversos e fontes para pesquisas também variadas, a análise da obra de viagens parece ainda não ter se esgotado, apontando para possibilidades interessantes de reflexão. Vale ressaltar que a produção bibliográfica sobre a temática dos viajantes europeus no Brasil, ou ainda sobre as pinturas de paisagem, é um campo de estudo consolidado e com expressivos resultados de pesquisas ${ }^{1}$. Acreditamos contribuir para esse debate propondo uma discussão sobre a as representações elaboradas sobre o Brasil no século XIX a partir dos relatos e das pinturas dos viajantes, com destaque para as obras de Jean Baptiste Debret e de Johann Moritz Rugendas. Em particular, procuramos examinar as representações construídas, salientando-se as relações entre as ideias de natureza e de civilização, e como as ideias difundidas por esses viajantes ajudariam na constituição de uma percepção sobre o Brasil e sua população, tanto para a própria sociedade brasileira como para os estrangeiros. Dialogando com os estudos produzidos sobre o tema, buscamos contribuir com o debate ao centrarmos nossa análise nas paisagens produzidas por Debret $e$ Rugendas à luz das categorias belo, pitoresco e sublime, por entendermos que as concepções estéticas se articulam às perspectivas políticas e às visões de mundo da época de produção dessas obras. Além desses conceitos, procuramos efetuar também uma reflexão em torno do conceito de paisagem, considerando-o como um conceito importante para a compreensão da formulação de representações sobre o Brasil no século XIX.

Entendemos que as obras, tanto os escritos quanto as obras pictóricas, produzidas por esses viajantes eram tributárias de uma nova percepção sobre a natureza, que implicaram na 
elaboração de representações sobre a paisagem. Nesse sentido, parece-nos enriquecedor a contribuição dos estudos da história da arte, da filosofia e da geografia cultural que nos ajudam a problematizar como as representações da paisagem são produzidas em um dado contexto histórico. Sendo a obra de arte um produto cultural não podemos desconsiderar que todo o contexto de sua produção, aí incluído a cultura em que está inserido seu produtor, influencia as escolhas, os recortes, as abordagens artísticas e estilísticas quanto ao objeto e tema representado (Oliveira, 2008, p. 220).

\section{A temática da paisagem e da natureza no século XVIII e XIX}

Um dos temas que predominará nos relatos dos viajantes que chegaram ao Brasil no século XIX será o da natureza e da paisagem. Com a instalação da Corte no Rio de Janeiro e, especialmente depois da independência, aportam ao país "artistas profissionais" ou não, com amplo manejo do desenho. Tanto artistas como viajantes comuns que aqui chegavam eram educados segundo alguns padrões estéticos, entre os quais os do pitoresco. Na linguagem estética do pitoresco os traços românticos, subjetivos e as sensações são ressaltadas. Destacam-se em termos de composição a arte dos jardins, a pintura de paisagens e a literatura romântica. Nas composições aparecem figuras mitológicas, místicas, imagens campestres, o elemento bucólico, animais, aspectos da natureza, as cores e a luminosidade.

O termo pitoresco é um vocábulo utilizado pela linguagem artística a partir de finais do século XVIII e seu uso tinha como finalidade designar uma nova categoria estética em relação tanto à paisagem natural quanto a representada, distinta da categoria sublime. O sublime convoca ao sentimento de temor reverencial diante da natureza, que se apresentaria grandiosa $e$ hostil. O pitoresco, por outro lado, evoca as imperfeições e as assimetrias das cenas repletas de detalhes curiosos e singulares que tem como objetivo remeter a uma imagem de uma natureza acolhedora e dadivosa. São valorizadas as irregularidades da natureza, mas sempre agradável, $e$ as fruições poéticas de um ambiente particular. A definição de pitoresco foi sistematizada na Inglaterra e designaria, nesse contexto, tanto o objeto natural quanto sua representação em um quadro. A expressão artística por excelência do pitoresco é a paisagem dos jardins ingleses. Segundo Guilio Carlo Argan (1991), o pitoresco se expressaria na "jardinagem", na arte de educar a natureza, com uma perspectiva de melhoramento, mas sem retirar-lhe a naturalidade que lhe seria própria. Na estética do pitoresco privilegia-se o que é característico, mutável e relativo, em contraposição ao sublime que aponta para o trágico, o infinito e o universal.

Muitos estudos sobre a estética do pitoresco foram efetuados no século XVIII, entre outros nomes podem ser citados o de Alexander Cozens (1717-1788) e seu filho John Robert 
Cozens, pioneiros na estética do pitoresco. O primeiro discutiu a noção de pitoresco em seu tratado Um novo método de auxílio à invenção no desenho de composições paisagísticas originais (1785-1786), no qual expõe um método de estimulo à imaginação fundamentado na convicção de que as sensações visuais se apresentam sempre de maneira variada e irregular espécie de "borrões" - e não através de esquemas geométricos, como definia a perspectiva clássica. A partir desse novo método os artistas procuravam captar a variedade das aparências, definindo os traços singulares das paisagens. Outro nome que pode ser mencionado é o de Sir Uverdale Price (1747-1829), que publicou Ensaio sobre o pitoresco (1794/1798), obra em dois volumes e de grande importância para a fixação da noção de pitoresco. No entanto, para efeito desse estudo, tomamos como referência Três ensaios sobre o pitoresco e o belo (1782), escrito por William Gilpin (1724-1804), que exerceu profunda influência sobre o gosto europeu de sua época, particularmente quanto à composição das pinturas de paisagem.

As paisagens pitorescas empregam normalmente tonalidades quentes e luminosas, que enfatizam a irregularidade e a diversidade dos objetos do mundo natural. Os cenários são compostos a partir de variado repertório: árvores, pássaros, efeitos de luz e céu, troncos caídos, poças de água, choupanas, animais no pasto, pequenas figuras. A estética do pitoresco utiliza-se ainda da associação entre paisagem e ruínas, particularmente daquelas recobertas de musgos $e$ trepadeiras, provocam a sugestão de imagens extraordinárias e sentimentais. E ainda a idealização de personagens "humildes".

Para se compreender a estética do pitoresco é preciso pensar também que em finais do século XVIII e primeira metade do XIX a ideia de natureza e sua apreensão estão se modificando. Raymond Williams chama atenção para o fato de que dois princípios sobre a natureza se apresentam concomitantemente. Um deles diria respeito à compreensão da natureza como "princípio de ordem", "do qual a mente ordenadora faz parte, e que pode ser reordenado e controlado pela atividade humana, através de princípios reguladores". Mas por outro lado, há uma natureza apreendida a partir da noção de um "princípio de criação". Nessa segunda perspectiva a "mente criadora" também faz parte e apreende as verdades de sua própria natureza que, por sua vez, se harmonizariam com as da natureza exterior (Williams, 1987, p. 177-178). Sobre esta questão está em jogo o que esse autor define como "separação da posse" e "separação do espírito" e que, em ambos os casos, a noção de natureza havia sido captada e transformada. Nesses princípios reconhece-se que os indivíduos fazem parte dessa força, mas que isso pode ser esquecido e de que deve aprender com essas forças, ao invés de se tentar controlá-las.

O final do século XVIII, particularmente na Inglaterra, onde o pitoresco floresce, é um momento marcado por intensas transformações da natureza, como por exemplo 
reaproveitamento de terras, drenagens e desmatamentos. Mas seria também um período assinalado em contrapartida por sentimentos de perdas, de melancolia e de arrependimentos. Essas transformações na natureza, por outro lado, provocaram uma mudança no gosto, de modo que se acentuou o "gosto pela natureza inata, pela terra inculta: o gosto pelo 'pitoresco', para usar o termo da época" (Williams, 1987, p. 178). Ocorria não apenas uma mudança de sensibilidade, mas uma mudança de gosto.

O século XVIII seria um momento importante de alterações na percepção estética e no entendimento da paisagem. As mudanças históricas em curso à época levariam às mudanças na concepção da produção artística. Nesse século, as classes sociais mais altas começavam a admirar as transformações da paisagem. A paisagem se tornaria uma forma de arte e seus traços expressariam à experiência do belo, do sublime e do pitoresco. Para Margarida Queirós (2006), a paisagem bela seria aquela agricultada, pastoral ou ajardinada. Segundo a autora, acompanhando o movimento de cercamentos (enclosure) das terras, de um sistema comunal de exploração a um sistema de propriedades privadas, "o belo e o pastoral tornaram-se os atributos da paisagem inglesa, em virtude de se ter iniciado uma mudança da paisagem na Inglaterra rural" (Queirós, 2006, p. 244).

No contexto inglês ocorreria a transição das áreas territoriais originalmente destinadas a reserva de caça (bosques) para parques com tratamentos paisagísticos. Para Williams seria nesse "complexo de ocupação territorial" que se processaria o desenvolvimento consciente do paisagismo e a "reinvenção" da paisagem. Para Williams,

Os proprietários rurais setecentistas, ao viajarem pelo continente europeu $e$ colecionarem quadros de Claude e Poussin, aprenderam novas maneiras de ver a paisagem $e$, ao voltarem para a Inglaterra, criaram novas paisagens para serem desfrutadas de suas próprias casas. (Williams, 1989, p. 170)

Haveria uma mudança de gosto na disposição dos parques decorativos. Essas mudanças implicariam transformações na representação das paisagens e o conceito mais elaborado sobre paisagem apareceria nas artes e nas concepções sobre jardins. No entanto, longe de inovarem, os ingleses estariam imitando os pintores italianos seiscentistas (Williams, 1989, p. 170).

O conceito de paisagem seria uma invenção do Renascimento e os pintores renascentistas responsáveis pela construção de uma nova percepção visual. Duas escolas da arte da paisagem se destacariam, a italiana e a holandesa. A pintura italiana seria sobretudo normativa, buscando representar o que a natureza deveria ser, reintroduzindo a mítica pastoral. Dentre os nomes representativos dessa escola podem ser citados os dos pintores Claude Lorrain e Nicolas Poussin. A escola holandesa, por outro lado, apresentava outra visão de mundo e a 
paisagem refletiria a natureza visível. Representativos dessa pintura seriam Jan van Goyen e Jacob Ruisdael, este último, resgatado um século mais tarde pelos românticos, se tornaria a base da concepção do sublime, e se consagraria como principal pintor holandês de paisagens.

Segundo Besse, a invenção histórica da paisagem na época do Renascimento estava relacionada à invenção do quadro em pintura, mas também da paisagem no próprio quadro e ainda à invenção da "janela". Ou seja, "a paisagem seria, portanto, o mundo tal como é visto desde uma janela, seja essa janela apenas parte do quadro, ou confundida com o próprio quadro com um todo. A paisagem seria uma vista emoldurada e, em todo caso, uma invenção artística" (Besse, 2014, p. 15). É em torno dessa problemática, que a história da arte passaria a considerar a "invenção" da paisagem na Europa do século XVI. Mas a noção de paisagem não diria respeito apenas às transformações estéticas, estaria relacionada ainda a uma forma de pensar o mundo e à apropriação da terra, do território. A uma maneira de conceber o mundo a partir de uma dada apreensão da natureza, e seu domínio, e da imaginabilidade do ambiente. Dessa maneira, o estético, o social, o político e o cultural seriam indissociáveis da compreensão de paisagem.

O termo landscape se originaria de landschap em holandês, que por sua vez derivaria do alemão landschaft, de origem medieval, que remeteria a uma associação entre o sítio e seus habitantes, a uma perspectiva ao mesmo tempo morfológica e cultural. É possível que landschaft tenha se originado de land schaffen, isto é, "criar a terra, produzir a terra." O termo holandês embora tenha o mesmo significado que o seu correspondente em alemão, se associaria às pinturas de paisagens realistas de começos do século XVI, relacionando-se às novas técnicas de representação renascentistas. Landscape em inglês é normalmente apresentado como "view of the land" ou "representation of the land". Em francês, paysage, também está associado às técnicas renascentistas, mas seu radical pays, de origem medieval, significa ao mesmo tempo "habitante" e "território". A paisagem seria, então, um espaço social.

O conceito de paisagem constitui-se de grande relevância para os estudos sócio-espaciais e tradicionalmente remete ao espaço abarcado pela visão de um observador, associando-se às artes plásticas, diria respeito também à representação visual e pictórica de um dado espaço, a partir da perspectiva de voo de pássaro (visão do alto) ou de um ângulo privilegiado qualquer. Dessa maneira, há um conteúdo profundamente visual e representacional da paisagem. Não obstante a polissemia do conceito, parece haver certo consenso de que a paisagem tem relação com visualidade. A paisagem seria a "superfície visível, material dos lugares" (Souza, 2018, p. 59).

O surgimento da noção de paisagem liga-se a uma maneira de ver e de conceber o mundo, de compô-lo como uma cena. É uma "porção do espaço apreendido com o olhar", mas 
é um processo que não se limita a receber de forma passiva os dados sensíveis, mas antes, organizar esses dados de modo a lhes atribuir sentido. Olhar não seria apenas um exercício da visão, mas produção de sentido, ou seja, atribuição de significação. Dessa maneira, a paisagem é sempre subjetivamente e culturalmente construída.

Com a arte da pintura, a partir da perspectiva, se conformaria uma visão da natureza em percepção sensível ou em processo seletivo de apreensão da realidade. Com a perspectiva se estabeleceria as regras de "uma redução e de um ajuntamento". Na pintura não se veria coisas isoladas, mas o elo entre elas, que resultaria na paisagem (Cauquelin, 2007, p. 85). A paisagem não existiria em si mesma, "mas na relação com o sujeito individual ou coletivo que a faz existir como uma dimensão da apropriação cultural do mundo" (Besse, 2014, p. 13).

Seguindo o argumento de Besse, dentre outras abordagens possíveis ${ }^{2}$, a paisagem poderia ser compreendida como uma "representação cultural", tanto coletiva quanto individual. Sem desconsiderar o ponto de vista estético, historiadores, antropólogos, geógrafos e sociólogos adotariam um "procedimento culturalista para recolocar/deslocar a paisagem dentro de uma interrogação geral sobre a sociedade" (Besse, 2014, p. 17-18). Além de estética, as paisagens são construções econômicas, religiosas, filosóficas, científicas, técnicas e políticas. Para esse autor, apresentando o pensamento de John Brinckerhoff Jackson, fundador da Revista Landscape (1951), o valor da paisagem não estaria apenas no ponto de vista estético. Expressando o diálogo entre a geografia humana e as ciências sociais, Jackson defendia a noção da paisagem como uma produção cultural. Diferente dos estudos do campo da arte, em que a paisagem é uma representação mental, a paisagem seria entendida como uma "realidade objetiva, material, produzida pelos homens", nesse sentido, sempre cultural, porque produzida dentro de um conjunto de práticas, e sempre simbólica. A observação das paisagens possibilita a compreensão das formas como o espaço foi organizado por dada sociedade. "Ler a paisagem é perceber modos de organização do espaço" (Besse, 2014, p. 25). Permite tanto o entendimento da forma de organização da sociedade como das representações e valores sociais que atuam na sociedade.

\section{As viagens pitorescas e narrativas sobre o Brasil no século XIX}

De acordo com Beluzzo, entre os viajantes que chegavam ao Brasil, "mais do que a descrição naturalista, predominam entre eles a abordagem romântica do passeio pelos arredores e pelos jardins, a visão do homem 'original' na floresta virgem ou a forte sensação da grandiosidade do universo" (Beluzzo, 1996, p. 18). Tanto a imagem quanto o texto que resultavam das viagens combinavam-se para "produzir aos olhos europeus a América possível, 
misturando deslumbramento e repulsa" (Guimarães, 2000). Está presente a preocupação com a observação e a descrição detalhada da paisagem e da natureza. A paisagem tornava-se, como chama atenção Belluzzo, um "tema indissociável da experiência do viajante do século XIX" (Beluzzo, ibidem).

No século XIX as representações são construídas face à tensão entre as concepções cientificistas e românticas do conhecimento do mundo. Tais elementos estão presentes na produção literária e artística dos viajantes de formações variadas. A apreensão intelectual do Brasil e a construção de uma narrativa sobre sua história estavam vinculadas à aproximação ou distanciamento da natureza ou da civilização. A natureza permeou todas as concepções de América e de Brasil desde o século XVI, adquirindo grande relevância para pensar sua representação e sua incorporação ao conhecimento da época.

As viagens pitorescas não se caracterizariam por serem simplesmente inventários ou repertórios, mas antes, uma série de imagens com a finalidade de ser uma força a "despertar o público para os valores do passado". O termo pitoresco era adotado também quando se tinha como proposta apresentar um "retrato" dos povos, não apenas de um ponto de vista político, mas um testemunho dos mais amplos aspectos das características de um determinado grupo visitado. No caso de Jean Baptiste Debret, o sentido de pitoresco em sua obra

[...] estava submetido às exigências de um discurso histórico em favor do qual o artista iria empregar suas imagens. Sua leitura do pitoresco passa, assim, pela necessidade de utilizar as imagens em seu discurso, o que situa sua produção entre os relatos que se diferenciam, pelo uso da imagem pitoresca, das obras de caráter científico. Através da iconografia, Debret consegue traçar um itinerário didático a ser percorrido pelo leitor, o qual deve chegar à leitura do Brasil tal qual ele a tinha concebido e coordenado através do duplo emprego da pena $e$ do pincel. (Lima, 2003, p. 38)

Jean-Baptiste Debret $^{3}$ (1768-1848) era primo de Jacques-Louis David, cujo ateliê começou a frequentar ainda muito jovem. Nesse espaço conviveu com personalidades artísticas $e$ ativistas e com intensas discussões artísticas e políticas. Sua formação corresponde às diretrizes da arte acadêmica francesa, bem como da assimilação dos princípios do neoclassicismo de David, conhecido como um renovador desse estilo, e que adotara como postura os princípios da inovação e da transformação para a criação de sua arte. Movido pelo anseio de mudança - no tema, no estilo e na concepção - David opôs-se às estruturas estáticas e padronizadas da Académie Royale de Peinture e Sculpture, reflexo da conjuntura política revolucionária em que vivia ${ }^{4}$.

O método de David se contrapunha ao procedimento de composição sintética, de pinceladas rápidas, característico da pintura do século XVIII e desenvolve paulatinamente um processo de criação que dá origem ao que pode ser nomeado como pintura ética, de traços 
heroicos, que se associava ao virtuoso, cujo exemplo é a tela "O juramento dos Horários", quadro exposto do Salão 1785 e que expunha o patriotismo e o sacrifício do indivíduo frente às necessidades do Estado. Esse "classicismo ético", com sentido claramente político, prepararia o caminho para a Revolução Francesa (Friedlaender, 2001).

De acordo com Valéria Lima ${ }^{5}$, o ponto chave da compreensão da obra de Debret está fundado na questão do realismo neoclássico, percebido pela autora como a ligação entre a inspiração davidiana e sua experiência no Brasil. Tratava-se de um realismo empírico, no qual a observação era o ponto inicial do desenrolar de todo processo de composição. Testemunhar o fato que originava o quadro era o elemento legitimador do realismo neoclássico, de um "realismo cuidadosamente trabalhado pela razão e pela prática pictórica". Essa forma de pintura seria ainda tributária da tradição enciclopédica do século XVIII, cuja forma de pensar contribuiu para que a pintura neoclássica "pudesse tratar todos os elementos do mesmo modo, considerando-os igualmente significativos para o conjunto da composição" (Lima, 2003, p. 1920). Seguindo tais princípios a pintura congregaria em si a força do testemunho, ponto que Debret procuraria deixar visível em seus textos, ou seja, a noção de veracidade ou de verossimilhança de suas obras.

Tomando outra posição frente a esse debate, Rodrigo Naves considera que haveria em Debret uma dificuldade em transpor os princípios neoclássicos para o Brasil, devido a questões como o caráter da monarquia portuguesa e a escravidão do país. Seus desenhos revelariam o esforço empreendido pelo artista diante de sua formação neoclássica e a realidade brasileira. Para Naves, Debret seria o primeiro pintor estrangeiro a perceber o que havia de "postiço e de enganoso em simplesmente aplicar um sistema preestabelecido — o neoclássico, por exemplo a representação da realidade brasileira” (Naves, 1995, p. 44-45). Em sua argumentação, Debret, ainda que mantendo a preocupação documental, imprimiu uma "dimensão a mais", que conferiria "uma nova realidade às cenas e objetos representados". Assim, julga que os desenhos do artista ultrapassariam o "aspecto puramente documental" que revelara tanto uma mudança de caráter formal de seu trabalho quanto uma melhor apreensão da vida o Brasil.

Ana Maria Belluzzo, por outro lado, à semelhança de Valéria Lima, aponta em O Brasil dos viajantes que:

Debret procura um ponto de vista impessoal, preceito de pintura histórica, na qual se havia formado com Jacques-Louis David. Relaciona-se com os temas que registra, colocando-se como narrador diante da realidade dos fatos. A presença in loco passa sempre um atestado de verdade. Não é por outra razão que Debret refere-se às próprias notas e desenhos como 'documentos históricos e cosmográficos'. A viagem pitoresca de Debret é proposta a partir do ponto de vista da Missão Artística Francesa no Brasil, tornada como correspondente da Academia de Belas Artes do Instituto da França. Traduz, portanto, um projeto civilizador de extensão cultural. 
[...] A atenção de Debret não se dirige para a construção da ideia de natureza, nem para o reconhecimento das riquezas naturais, nem de uma humanidade em estado natural. Debret terá de centrar a atenção no estado geral da sociedade, buscando apreendê-la com base no entendimento da transformação da natureza em cultura, do natural em civilizado. A concepção procede da ilustração francesa, acrescida do interesse pelas particularidades dos povos. (Beluzzo, 1996, p. 82-83)

Debret veio ao Brasil na famosa "Missão Artística Francesa". Sem trabalho, juntamente com outros artistas e profissionais franceses malvistos na corte francesa no contexto da restauração monárquica, chegaria ao Brasil em 1816, permanecendo até 1831. Vieram com a finalidade de organizar, a pedido da corte portuguesa, uma Academia de Belas Artes ${ }^{6}$. Os artistas franceses chegaram às terras brasileiras logo após a morte de D. Maria I, rainha de Portugal. Este fato seria o primeiro que lhes mobilizaria, pois era preciso organizar, "com brilho e pompa, a cerimônia de aclamação do novo monarca brasileiro, celebração para a qual se empregaram os talentos franceses". Nas palavras do próprio Debret,

O falecimento da Rainha já estabelecia o programa de um monumento para o arquiteto, de uma figura para o escultor, de um quadro histórico para o pintor, de um retrato para o gravador, deixando-lhes ainda a perspectiva da elevação ao trono do Príncipe Regente, seu filho e sucessor. (Debret, 1940, p. 116)

Para Jean-Baptiste Debret era o começo de uma movimentada carreira como pintor da corte portuguesa, executando retratos da família real e dos ministros do monarca, bem como documentando os momentos importantes da história da monarquia portuguesa e da dinastia de Bragança no Brasil. Junto a essas funções, tornou-se também membro fundador e pintor de história da Academia Imperial de Belas Artes, inaugurada em 1826. Pouco a pouco Debret conquistava um espaço importante tanto por seu desempenho na corte quanto pelos trabalhos na Academia. Sua permanência e envolvimento com questões da experiência brasileira proporcionaram-lhe, nesse sentido, a "constituição de um corpus iconográfico que seria a base material de sua interpretação e relato sobre o Brasil" (Debret, 1940, p. 27) ${ }^{7}$. De acordo com o próprio artista, desejava apresentar uma "biografia nacional" e oferecer

[...] aos estrangeiros um panorama que extrapolasse a visão de um país exótico $e$ interessante apenas do ponto de vista da história natural. Acreditava que o Brasil merecia estar entre as nações mais civilizadas da época e que a elaboração de uma obra histórica a seu respeito seria uma contribuição valiosa para que esta justiça se cumprisse. (Debret, 1940, p. 116)

A chegada ao Brasil foi marcada, a exemplo da descrição de outros viajantes, pelo deslumbramento com a natureza. No alvorecer da manhã seguinte a chegada, ainda sem desembarcar, Debret observa que os tripulantes do "Calphe", não se sentiram menos felizes 
mesmo sendo despertados às cinco horas pelo tiro de canhão que registrava a abertura do porto, indicando a "aurora" que descortinaria "pela primeira vez, a entrada interior da magnífica baía do Rio de Janeiro, citada por inúmeros viajantes como uma das maravilhas do mundo" (Debret, 1940, p. 116). Continuando a descrição, que seria registrada na prancha $n^{\circ} 3$, diz:

Examinando atentamente esse quadro precioso, cujos detalhes e colorido, absolutamente novos para nós, se faziam mais sedutores à medida em que o sol os tornava mais inteligíveis, descobrimos, finalmente, o panorama encantador desse lugar delicioso, coberto de todos os lados por um verde-escuro em geral brilhante, ainda resplandecendo de gotas de orvalho que fecundara durante a noite os frutos abundantes que percebíamos através da folhagem, graças à sua cor alaranjada. Do ponto em que estávamos, podíamos descortinar cercas de limoeiros em torno de plantações de café e de laranjeiras, situadas no flanco das colinas arborizadas e em parte surribadas a pequena distância das casas de residência, cuja nota de cor branca formava pontos de esmalte na verdura das montanhas circunvizinhas. Mais longe, nas partes altas, quedas d'água escorrendo pela rocha nua formavam igualmente pontos brancos, porém cintilantes como estrelas. À beira mar, as colinas menores recobriam-se de uma vegetação mais baia, em verdade, porém coroada de palmeiras esguias, cujas palmas pendiam cachos de cocos maduros, ainda protegidos pela casca lenhosa, marrom e peluda. Esse panorama de abundância universal nos indicava o motivo do vai-e-vem de numerosas barcas carregadas, que desembocavam de todos os lados dos rios afluentes e se dirigiam para o porto da cidade, que percebíamos ao longe. Ao primeiro movimento de admiração sucedeu o desejo de fixar-lhe a lembrança. Tomando do lápis apontado na véspera pôs-me a traçar com cuidado o panorama do lugar em que nos encontrávamos. (Debret, 1940, p. 116-117)

Seu Viagem pitoresca e histórica ao Brasil foi publicado inicialmente no formato de fascículos, como era então o costume. Os três volumes, como atualmente se conhece, foram publicados em 1834, 1835 e 1839. E desde a sua volta a Europa, Debret se empenhou na organização do material que havia coletado no Brasil. Os volumes continham cada um aproximadamente cinquenta pranchas e as imagens eram acompanhadas de textos explicativos escritos pelo próprio artista. Os textos não são simplesmente descrições das imagens, mas comentários sobre os fatos ou costumes a elas relacionados ${ }^{8}$.

Nesta obra, Debret procura acompanhar o que compreende como sendo os diversos momentos da "marcha progressiva da civilização no Brasil". Desse modo, sua argumentação segue, de certo modo, a estrutura já apontada por outros viajantes, traduzindo uma forma comum de pensamento quanto ao entendimento do Brasil. Assim, o plano de sua obra segue as descrições e comentários sobre os indígenas que considerava como um "povo na infância" (tomo I, vol. I) e sobre "os povos civilizados" (tomo I, vol. II), nesse particular inclui os brancos, os mulatos e os negros escravos. O tomo II, volume III a descrição país, de seus hábitos, costumes e cultura. 
A princípio parece que Debret estabelece uma divisão racial em sua obra, separando as experiências de indígenas, de negros e de brancos. Essa divisão minimiza a complexidade de sua interpretação sobre país (Lima, 2007). País que para Debret estivera durante muito tempo subjugado a "arbitrariedade e opressão dos governos portugueses" e devido a essa situação o brasileiro se sentia humilhado. Para ele, a colônia se manteria estacionária até a chegada da corte portuguesa, pois antes havia somente a exploração do território, sem nenhuma perspectiva de crescimento autônomo. O estabelecimento da corte desencadearia um processo de regeneração, "cuja continuidade estava nas mãos dos brasileiros, conduzidos à emancipação política pelo herdeiro da Coroa portuguesa" (Debret, 1940, p. 29). Para o pintor a população brasileira estava apta a conduzir tal processo, mas sendo necessário, no entanto, investir em dois caminhos: o da miscigenação racial e o da educação.

As impressões e as considerações de Debret sobre o Brasil tinham como fonte de inspiração a cidade do Rio de Janeiro, a partir de onde ele interpretaria não apenas a cultura e a sociedade brasileira, mas também a política e a economia. Para o pintor, o Rio de Janeiro era o centro de onde se irradiava a civilização para todas as outras partes do território brasileiro.

Os comentários que elabora sobre a cidade são de um modo geral positivos. Elogios são feitos à paisagem, a população e às construções civis e religiosas. Destacam-se sobretudo as apreciações feitas por Debret a respeito das edificações: casas, igrejas, monumentos, obras públicas. A descrição da topografia e do plano geral da cidade, bem como da natureza e de sua conformação é efetuada de uma maneira concisa e objetiva. Desse modo, percebe-se que Debret constrói sua "obra histórica" a partir do espaço urbano, e dele, se apropria dos fatos e acontecimentos que julga mais importantes para compor sua narrativa.

Para Debret, não obstante a força sublime que a natureza selvagem exerceria sobre quem a observa, o homem civilizado seria ali mais forte também. Apesar da imponência da vegetação, a vontade do homem branco sobrepõe-se a do indígena, já que estes estão submetidos a um projeto civilizador que os destituiria de sua identidade.

Um exemplo dessa perspectiva é a cena representada na prancha 1 (Tomo II, vol III) (Figura 1). Nessa pintura sentimos a exuberância da floresta e da vegetação, registrada em traços precisos e no uso das diferentes tonalidades de verde. De acordo com descrições do próprio artista, percebemos que a imagem foi elaborada com a finalidade de mostrar a força da natureza, pois em primeiro plano se destaca o "rio que se precipita através das florestas virgens, abrindo passagem pelo deslocamento das árvores que carrega na enxurrada de sua forte correnteza", além de árvores derrubadas por fortes ventos. Compõe a paisagem ainda "três soldados índios civilizados" que regressavam após a devastação de uma pequena aldeia 
selvagem, com mulheres e crianças, atravessando o rio por uma árvore arrancada apoiada sob um rochedo.

Para indicar o movimento evolutivo das sociedades indígenas e que essas pudessem informar aos leitores os diferentes estágios de civilização alcançados por esses povos, Debret compõe então uma série de pinturas. Para a elaboração dessas imagens valeu-se de informações coletadas por Martius e Spix.

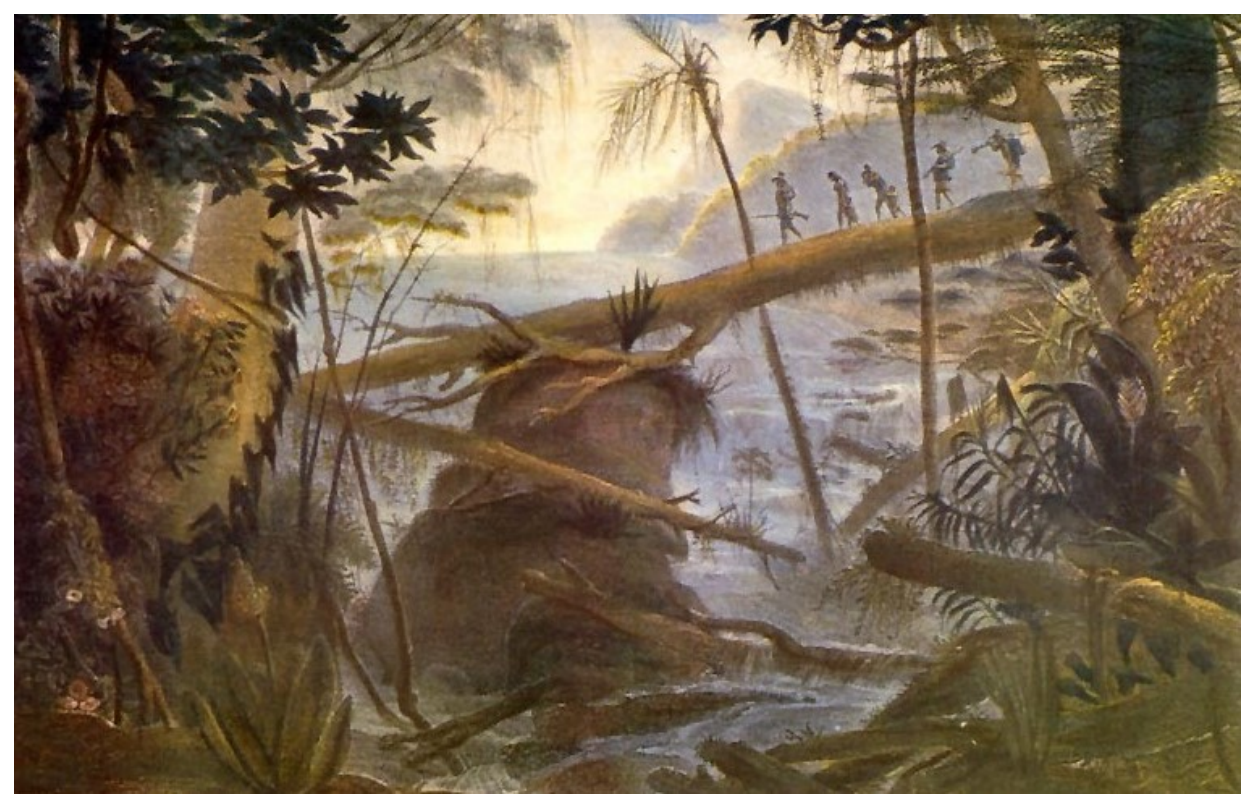

Figura 1: Florestas Virgens do Brasil, nas margens do rio Paraíba. (Debret, 1940)

É preciso registrar também a filiação de Debret com relação à compreensão da marcha da civilização, a uma perspectiva histórica escalonar ou de marchas para a civilização de acordo com o pensamento e ideais iluministas do século XVIII, marcada pela crença de história progressiva e que conduziria todos os povos a um mesmo estágio de civilização.

Outro artista-viajante a publicar uma obra que seria também uma "viagem pitoresca" é Rugendas. Johann Moritz Rugendas (1802-1858) é considerado como um pintor de primeira grandeza. Descendente de uma família de artistas e de pintores de Augsburgo na Baviera, veio ao Brasil por iniciativa de Karl C. von Langsdorff, cônsul-geral da Rússia, em 1825. Após uma excursão pelos Urais, Langsdorff obteve do czar o consentimento e apoio para realizar uma expedição científica pelo sertão brasileiro. Rugendas foi então contratado como desenhista da missão, mas logo que chegou ao Brasil abandona os companheiros e passa a viajar por conta própria, sendo substituído na expedição por Amien-Adrien Taunay.

Diferente de outros viajantes, Rugendas não descreveu o itinerário de sua viagem, mas redigiu um estudo geral sobre o Brasil que acompanharia a publicação de seus desenhos. $\mathrm{Na}$ 
volta a Europa em 1835, reuniu os desenhos feitos no Brasil e os publicou em uma edição luxuosa, em formato bilíngue, francês e alemão, pela litografia Engelmann de Paris, considerado o melhor e mais ilustre estabelecimento desse gênero na época. Rugendas volta ao Brasil mais uma vez, entre 1846-1847, percorre a América do Sul e o México, retornando a Europa com uma impressionante coleção de desenhos e de pinturas. Lança uma obra sobre o México no feitio da publicada sobre o Brasil.

Das aquarelas, quadros a óleo e desenhos, só uma parte, correspondente a sua primeira viagem ao Brasil, foi publicada e fez parte das ilustrações de Viagem pitoresca através do Brasil ${ }^{9}$. Mais que um hábil pintor, Rugendas é descrito como possuindo uma percepção aguda para escolher uma cena curiosa e característica, uma paisagem típica. Assim como outros viajantes suas observações representaram cenas diversas da sociedade brasileira, desde suas paisagens a seus costumes e população.

Viagem pitoresca através do Brasil se insere no conjunto de obras, a exemplo da de Debret, em que se procura compreender os povos e seus costumes, formando assim um discurso histórico a ser apresentado ao público europeu de outras nações. Procura em sua obra captar o que daria ao Brasil o seu caráter peculiar. Para tal fim sua obra se divide nos tópicos: paisagens, tipos e costumes, usos e costumes e a vida dos europeus. Assim como Debret, a descrição ou a história da "civilização" brasileira é contada considerando suas peculiaridades e a presença das três "raças" e seu mestiçamento.

Com relação à noção de história, Rugendas também opera com a noção de graus de civilização. Mas seu tom nem sempre é positivo. A respeito dos indígenas, por exemplo, considera que os relatos dos mais antigos viajantes, como Léry e Staden, apontavam que na época da conquista, os nativos estavam em um "estádio de civilização mais elevado" do que aquele em que ele via e a causa principal dessa "decadência" se devia as relações estabelecidas com os portugueses.

Em muitas das descrições de Rugendas, a natureza tropical é representada de maneira vigorosa e constitui uma imagem poderosa: a de uma natureza excessiva e provedora, em meio à qual o homem se perderia, tornando-se minúsculo e impotente. A natureza é tomada como objeto para a pesquisa científica e como inspiração artística, provocando sensações e ações tanto positivas quanto negativas, confortantes ou não, para aqueles que a observam.

\section{A estética do sublime na literatura de viagem}

Nem tudo é simplesmente belo na natureza. Frente a certos espetáculos ou circunstâncias, que apesar de não ameaçar os viajantes diretamente, os colocavam, contudo, 
frente à sua fragilidade, fazendo com que experimentassem de modo paradoxal um prazer excessivo ou negativo: o sublime. Aos poucos ocorreria a substituição de um panorama aterrador medieval, por um cenário sublime em que as montanhas, os céus noturnos, os desertos e a vida selvagem se tornariam objetos de grande interesse. "O valor das paisagens deixaria de ser decidido em função de critérios estéticos formais (harmonia, cromática ou proporção), ou de origem utilitária, para depender do potencial que os lugares revelassem de elevar o espírito humano ao sublime" (Queirós, 2006, p. 245). O termo sublime remonta ao período da antiguidade grega e ao Tratado de Longinus, Do Sublime, traduzido para o inglês em 1712. No século XVIII, o mito do sublime e do terrífico estava representado pelas forças cósmicas e da natureza. Como exemplo, o impacto causado pela visão das florestas, das serras e rochedos pintados por Rugendas, que ao desarmar-lhe a observação traduz um momento singular no registro da paisagem (Figura 2 ).

As florestas nativas constituem a parte mais interessante das paisagens do Brasil; mas também a menos suscetível de descrição. Em vão procuraria o artista um posto de observação nessas florestas em que o olhar não penetra além de poucos passos; as leis de sua arte não lhe permitem exprimir com inteira fidelidade as variedades inumeráveis das formas e cores da vegetação em que ele se vê envolvido. É igualmente impossível suprir essa falta por meio de uma descrição e muito erraria quem imaginasse consegui-lo através de uma nomenclatura completa ou de uma repetição frequente de epítetos ininteligíveis ou demasiado vagos. O escritor vê-se manietado pelas regras da sã razão, $e$ pela teoria do belo, dentro de limites tão estreitos quanto os do próprio pintor e que é dado somente ao naturalista transpor.

[...] Em vão tentaríamos exprimir em palavras a graça $e$ a beleza desses seres que os poetas, à míngua de expressões capazes de pintá-los, nos apresentam como a própria perfeição. [...] Aqui a natureza produz e destrói com o vigor e a plenitude da mocidade: dir-se-ia que revela com desdém seus segredos $e$ tesouros diante do homem, o qual se sente atônito e humilhado ante essa força e essa liberdade de criação.

[...] Se, de um ponto mais elevado ou desbastado, o olhar consegue alcançar as montanhas, depara com as massas ousadas desenhadas nas cadeias graníticas do interior; e mesmo nas florestas veem-se, não raro, blocos de rochedos tendo no seu cimo achatado jardins de belas flores. Quanto mais se avança nessas florestas, menos aberturas se encontram; pode-se andar durante vários dias sem que o céu se mostre senão de quando em quando, através das abóbadas aéreas cuja verdura cobre o viajante. A alma sente-se exausta $e$ oprimida; anseia por uma nesga de céu, deseja rever as constelações que, mesmo sobre mares inimigos, são o consolo e a esperança do navegante.

Finalmente o horizonte se alarga: abandona-se a noite espessa das florestas em troca das colinas do interior; respira-se afinal o ar das montanhas e saúda-se o firmamento. (Rugendas, 1998, p. 20-22) 


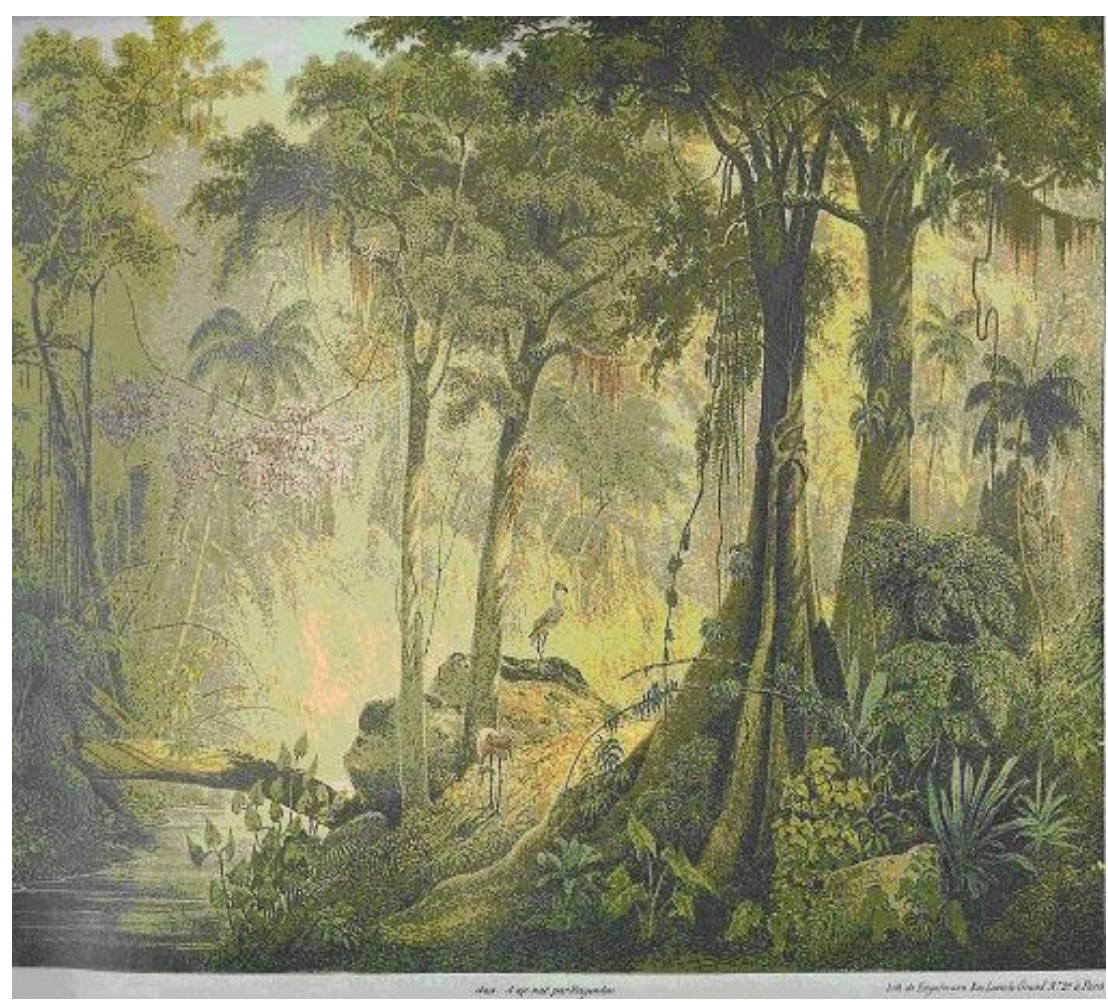

Figura 2 - Forèt vierge près Mantiqueritipa dans la province de Rio de Janeiro. (Rugendas, 1998)

Lendo tal passagem vemo-nos diante talvez do que William Gilpin nomeou de "pitoresco sublime" (Gilpin, 1982, p. 17). Diante do atordoamento descrito e mesmo da opressão colocamo-nos perante o sublime. Dentre os que se dedicaram a fazer tal discussão no século XVIII e que influenciaram as perspectivas estéticas ainda no século XIX, pode-se destacar os estudos de Edmund Burke, Uma investigação filosófica sobre a origem de nossas ideais do sublime e do belo (1757), que posteriormente contribuiriam para as discussões de Emmanuel Kant sobre o conceito de sublime, efetuadas em Observações sobre o sentimento do belo e do sublime (1764) e na Crítica da Faculdade do Juízo (1790) ${ }^{10}$.

Se o belo nos coloca diante de um sentimento de felicidade e a um jogo harmônico de nossas faculdades, a experiência estética do sublime, por outro lado, produziria no indivíduo primeiro o sentimento de uma suspensão das forças vitais, que violentaria, de certo modo, a imaginação. Em Kant "essa violência que ultrapassa as formas sensíveis a ponto de romper os limites, todavia remete-nos a nós mesmos: às Ideias da razão que levam a um mundo suprassensível, que nunca pode ser conhecido" (Ribon, 1999, p. 34). A fonte do sublime estaria no próprio indivíduo, que tem a capacidade de diante da natureza "absolutamente imensa" e "infinitamente poderosa" ver despertar a sua força interior de resistir "não apenas à onipotência da natureza", mas às forças da própria natureza humana, que deveriam submeter-se à ordem racional (Ribon, 1999, p. 34). 
Para Kant as sensações produzidas por um objeto estão relacionadas à noção de satisfação desinteressada e ao que agrada universalmente sem conceito. O prazer desinteressado não teria função prática ou utilitária, pois a contemplação estética não teria como finalidade nenhum conhecimento objetivo. Embora não desconsidere o belo artístico, concebe que existiria uma imediatez do belo natural, ou seja, o prazer que nos proporciona faz nosso juízo estético refletir sem que houvesse a mediação de um conceito ou de perspectivas culturais. $\mathrm{O}$ importante é a apreensão da fruição estética e não propriamente a formulação de julgamentos racionalmente elaborados. O que move Kant é pensar o modo pelo qual o sujeito compreende as coisas a partir de suas sensações, mas sem que haja a intermediação das apreciações cognitivas efetuadas pela razão.

Assim como Kant, Edmund Burke autor de Uma investigação filosófica sobre a origem de nossas ideias do sublime e do belo, também parte do pressuposto de que não há equivalência entre as esferas da estética e da razão. Ou seja, os domínios da estética são os da "finalidade sem fim". Por outro lado, diferentemente de Kant, julga que os fundamentos da apreciação estética estão nas próprias coisas e em suas propriedades. Compreende ainda que os padrões da razão $e$ do gosto "sejam os mesmos para todo o gênero humano" (Burke, 1993, p. 21).

Quanto à definição de sublime afirma que essa categoria estética age sobre

Tudo que seja de algum modo capaz de incitar as ideias de dor e de perigo, isto é, tudo que seja de alguma maneira terrível ou relacionada a objetos terríveis ou atua de um modo análogo ao terror constitui uma fonte do sublime, isto é, produz a mais forte emoção que o espírito é capaz. (Burke, 1993, p. 48)

Tais considerações sobre as obras de Kant e Burke ajudam-nos a pensar como os estrangeiros elaboravam suas impressões sobre a América, e particularmente o Brasil. Conhecendo e compartilhando dessa linguagem estética, nossos viajantes estabeleciam em suas narrativas e iconografias o impacto da natureza frente ao homem e cuja força provocava uma ação na conformação dos homens. Vale ressaltar, como chama atenção Carla Mary S. Oliveira, em resenha da obra Debret e o Brasil: obra completa (1816-1831), de Júlio Bandeira e Pedro Corrêa do Lago (2007), que a obra de arte não seria apenas imanência. Remetendo a Ernest Cassiser, e seu A Filosofia das formas simbólicas, Oliveira aponta para o fato de que a arte "remete a estruturas muitas vezes submersas para o observador desavisado, posto que estão fundeadas na cultura à qual o artista pertence e que possui, ela mesma, determinados "valores simbólicos"” (Oliveira, 2008, p. 218).

Sobressai por todo o século XIX, uma preocupação com a civilização e com o progresso, cujos modelos eram fornecidos pela Europa. Por outro lado, outros costumes conflitantes com as perspectivas civilizadoras das elites eram progressivamente combatidos e considerados 
"bárbaros" e "selvagens". Dos países europeus, através de suas elites políticas e intelectuais, partiam as projeções do que se compreendia e do que se desejava que fosse a civilização. No Brasil, desejava-se não apenas um outro lugar diferente, mas um outro lugar considerado melhor, isto é, o mundo europeu, o mundo civilizado. Subjacente a este sentimento estava à ideia de que a história do mundo ocidental seria portadora de um conjunto de características às quais se atribui o nome de civilização, que torna o conceito ao mesmo tempo includente $e$ excludente (Naxara, 2000).

Quanto à imagem do Brasil continuava a se apresentar ao exterior uma ideia de "terra encantada", portadora de riquezas naturais, com belo clima, rios, flores e animais, e também a decepção com o atraso e a perspectiva do progresso. Desse modo, o índio e a natureza constituíam o foco principal das atenções. Agora, entretanto, fazendo parte de estudos sistemáticos e classificatórios. A ideia de progresso tão presente na Europa reforçava sua imagem e em contrapartida deformava o Outro pela comparação (Leite, 1996, p. 48).

Junto à representação da natureza, encontra-se presente no mesmo contexto, a questão da presença negra na população brasileira e a escravidão. Ao longo do século XIX, a busca da compreensão ou a análise da população brasileira perpassam pelas explicações das teorias raciais. No Brasil, o povo não correspondia ao imaginário que se projetava, ou seja, a de uma nação branca e civilizada. O povo, de acordo com as elites, aproximava-se do atraso e da barbárie, era informe e sem identidade, caracterizado por sua pequenez, frente à exuberância da natureza. Sobre esses aspectos contribuíram bastante as opiniões emitidas por estrangeiros.

Nesse sentido, os viajantes esforçavam-se por encontrar no Brasil os sinais de alteridade e por salientar o "Outro". Nesse percurso, o peculiar era identificado com o exótico e ao mesmo tempo idealizava-se o civilizado. No afã de se apresentarem de modo distinto dos habitantes brasileiros, os estrangeiros frisavam os traços do que julgavam ser os modos civilizados.

As representações sobre o Brasil se faziam ainda tendo como pano de fundo as noções de meio e de raça e frente às tensões entre natureza e civilização. O código civilizado marcava cada etapa da travessia do Atlântico em direção à América. Muitos viajantes expressam grande surpresa com relação à população negra das cidades brasileiras, e o primeiro contato se fazia normalmente através do Rio de Janeiro.

Durante todo o século XIX, os viajantes que chegavam ao Brasil se defrontavam com significativo número de negros na população em relação aos brancos. Duas posturas distintas delimitavam as ações $e$ as atitudes desses observadores. Por um lado, estavam os que observavam o número significativo de africanos e de descendentes no conjunto da população brasileira, como por exemplo, Martius. Por outro lado, havia os que ignoravam a presença negra 
na população e apenas mencionavam os brancos como "brasileiros", ou incluíam em seus relatos informações sobre os indígenas, como é o caso do Príncipe Maximiliam Wied-Neuvied.

Debret, por outro lado, seguindo a estrutura de sua obra, ou seja, a de apresentar os diferentes estágios de evolução dos grupos que compõe a sociedade brasileira, dá grande espaço aos negros, principalmente por considerar o papel desempenhado por essa parcela da população da sociedade brasileira do século XIX. Para esse artista, os negros não deveriam ser percebidos apenas como sustentadores da economia, mas como possibilidades de avanço da marcha para o progresso. Debret ainda dedica uma parte de sua obra aos castigos infringidos aos escravos.

No Brasil, no que tange aos estrangeiros diante das representações sociais construídas, não escapavam também de suas observações os vários aspectos das cidades brasileiras do século XIX. Se depreende dessas representações sobre a cidade descrições das ruas e dos logradouros públicos. Ruas estreitas, tortuosas, inclinadas e irregulares, são fontes de observações insistentes dos viajantes estrangeiros e parecem se constituir em elemento de projeção de um imaginário total e de compreensão da sociedade brasileira. $\mathrm{O}$ ritmo irregular e a desordem acabaram por definir a cidade, por exemplo, como um "espaço confuso", acentuado ainda mais pelo seu caráter heterogêneo e pitoresco. De um modo geral, estas apreciações remetem para a ideia de desorganização e para a necessidade de uma ampla reformulação dos espaços urbanos, que deveriam ser "desodorizados" e reconstituídos de acordo com os padrões de vigilância, limpeza e regularidade que caracterizam as sociedades modernas. Remetiam ainda a uma ideia de desorganização política. Os logradouros públicos também constituíam alvo de preocupação, porque para os viajantes, nesses locais se encontravam frequentemente multidão multiforme, composta principalmente por africanos (Figura 3). 


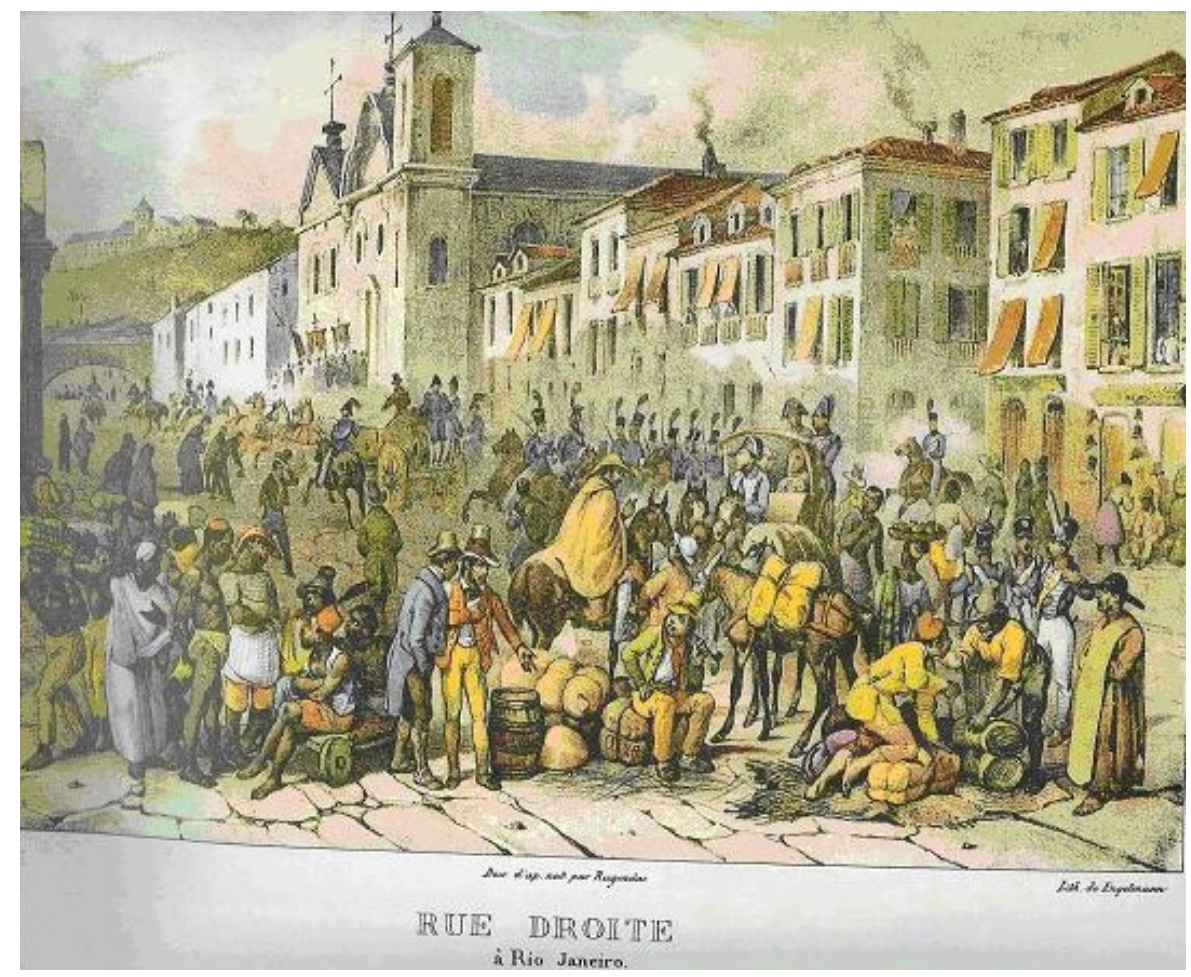

Figura 3 - Rue Droit à Rio de Janeiro. (Rugendas, 1998)

Pontos de vista como esses ajudaram os viajantes a projetarem valores e a elaborar determinações fundamentais de identificação da sociedade brasileira que não se restringiriam as percepções meramente de estrangeiros, mas sob muitos aspectos compartilhados pelos nacionais. Progressivamente tais ideais ajudariam nas construções de uma perspectiva quanto a uma identidade inconclusa com relação à história do Brasil e da sociedade brasileira, marcada pelas perspectivas de arcaísmo e de incapacidade de organização (política, urbana, social). Perpassava a noção de que a sociedade seria incapaz de se auto organizar e caberia pôr fim ao Estado esse papel/função de regulador. Constitui-se a partir do século XIX um projeto político centralizador, no qual coube a intelectualidade e aos políticos grande força de atuação. Esses pontos de vista entrelaçavam argumentos racionais e a constituição de imagens, de forte apelo emocional, portanto, de representações estéticas, que fomentavam a constituição de um conjunto de imagens e de ideais sobre o nacional, no qual estavam presentes utopias acerca da boa sociedade, da boa cidade e de civilização.

\section{Referências}


ARGAN, Guilio Carlo. Arte Moderna - Do Iluminismo aos movimentos contemporâneos. São Paulo: Companhia das Letras, 1992.

BANDEIRA, Júlio; LAGO, Pedro Corrêa do. Debret e o Brasil: Obra Completa 1816-1831. Rio de Janeiro: Capivara Editora, 2007.

BELUZZO, Ana Maria. A propósito d'O Brasil dos Viajantes. Revista Usp, São Paulo (30):8-19, jun./ago. 1996.

BESSE, Jean-Marc. O gosto do mundo: exercícios de paisagem. Rio de Janeiro: EdUERJ, 2014.

BURKE, Edmund. Uma investigação filosófica sobre a origem de nossas ideias do sublime e do belo. Campinas/SP: Papirus, 1993.

CAUQUELIN, Anne. A invenção da paisagem. São Paulo: Perspectiva, 2007.

DEBRET, Jean-Baptiste. Viagem Pitoresca e Histórica ao Brasii. Trad. Sérgio Milliet. Tomo I (Vol I e II). São Paulo: Livraria Martins Editora,1940.

DIENER, Pablo; COSTA, Maria de Fátima. Rugendas e o Brasiı. São Paulo: Capivara, 2002.

FRIEDLAENDER, Walter. De David a Delacroix. São Paulo: Cosac Naif, 2001.

GILPIN, William. Trois essais sur le beau pittoresque. Sur les voyages pitoresques et sur l'art d'esquisse les paisajes, suivi d'un poème sur la peinture de paisaje, paru en 1792, et traduit de l'anglais par le Baron de Blumesnstein en 1799. Paris: Editions du Moniteur, 1982.

GUIMARÃES, Manoel Luiz Salgado. História e natureza em Von Martius: esquadrinhando o Brasil para construir a nação. História, Ciências, Saúde — Manguinhos, vol. VII (2), 389-410, jul.-out. 2000.

KANT, Immanuel. Observaçôes sobre o sentimento do belo e do sublime. Campinas/SP: Papirus, 1993.

LEITE, José Roberto Teixeira. Dicionário crítico da pintura no Brasii. Rio de Janeiro: Arlivros, 1988. 
LIMA, Valéria. A viagem pitoresca e histórica de Debret: por uma nova leitura. Tese (Doutorado em História). Campinas/São Paulo: Universidade Estadual de Campinas, 2003.

LIMA, Valéria. Uma viagem com Debret. Rio de Janeiro: Jorge Zahar, 2004.

LIMA, Valéria. J.B. Debret, Historiador e Pintor. A Viagem Pitoresca e Histórica ao Brasil (18161839). Campinas: Editora da Unicamp, 2007.

NAVES, Rodrigo. Debret, o neoclassicismo e a escravidão. In: A forma difícil: ensaios sobre arte brasileira, 1995.

NAXARA, Márcia Regina Capelari. Cientificismo e sensibilidade romântica: em busca de um sentido explicativo para o Brasil no século XIX. Brasília: UnB, 2004.

NAXARA, Márcia Regina Capelari. Natureza e Civilização: sensibilidades românticas em representações do Brasil no século XIX. In: BRESCIANI, Stella; NAXARA, Márcia (orgs.) Memória e (Res)sentimento - Indagações sobre uma questão sensível. Campinas/SP: Editora da Unicamp, 2001.

OLIVEIRA, Carla Mary S. O cotidiano oitocentista pelos olhos de Debret. Saeculum - Revista de História; João Pessoa, jul./ dez. 2008, p. 215-225.

QUEIRÓS, Margarida. A pintura de paisagem: uma matriz para a observação, reflexão e aprendizagem. Cadernos de Geografia, Coimbra, FLUC, n² 24/25, 2005-2006, p. 241-251.

RIBON, Michel. A arte e a natureza. São Paulo: Papirus Editora, 1991.

RUGENDAS, Johann Moritz. Viagem pitoresca pelo Brasii. Tradução Sérgio Milliet. Coleção Reconquista do Brasil. 3a Série, 8. São Paulo: Editora Itatiaia Limitada/Editora da Universidade de São Paulo, 1998.

SOUZA, Marcelo Lopes de. Paisagem. In: Os conceitos fundamentais da pesquisa sócio-espaciai. Rio de Janeiro: Bertrand Brasil, 2018.

TREVISAN, Anderson Ricardo. Velhas imagens, novos problemas: a redescoberta de Debret no Brasil modernista (1930-1945). Tese (Doutorado em Sociologia). São Paulo: Universidade de São Paulo, 2011. 
TREVISAN, Anderson Ricardo. Arte, memória e sociedade: Jean-Baptiste Debret e sua (re)descoberta na primeira metade do século XX no Brasil. RESGATE - vol. XX, N0 23 - jan./jun. 2012, p. 18-27.

WILLIAMS, Raymond. O campo e a cidade na literatura e na história. São Paulo: Companhia das Letras, 1987.

${ }^{1}$ Vale registrar que a produção intelectual é bastante rica e ao longo das últimas décadas, os pesquisadores têm
publicado importantes estudos resultados de dissertações e teses, bem como catálogos raisonnés das obras de pintores
do século XIX, com rigorosa análise conceitual da estética da época de produção das obras dos viajantes e as
manifestações artísticas aplicadas ao contexto cultural brasileiro. Ver para os viajantes analisados nesse artigo:
Bandeira; Lago; Diener; Costa, 2002 .
${ }^{2}$ O geográfico apresenta cinco portas conceituais e percursos teóricos de abordagem da paisagem: a paisagem como
uma representação cultural e social; a paisagem como território fabricado e habitado; paisagem como ambiente
material e vivido das sociedades humanas; a paisagem como uma experiência fenomenológica; a paisagem como
projeto (Besse, 2014, p. 11-66). ${ }^{3}$ As referências a Jean-Baptiste Debret na bibliografia brasileira são significativas. Sobre a fortuna crítica de Debret ver, dentre outros: Lima (2007, p. 40-61); Bandeira \& Lago (2007); Trevisan (2011) e (2012); Leenhardt (2013); Diener (2013);

${ }^{4}$ Sobre a biografia do artista, ver a apresentação de Jean-Baptiste Debret por Rubens de Borba Moraes, Diretor em 1940 da Biblioteca Histórica Brasileira. In: Viagem Pitoresca e Histórica ao Brasil. Trad. Sérgio Milliet. Tomo I (Vol I e II), 1940.

${ }^{5}$ Além da obra citada nesse artigo, Uma viagem com Debret (2004), Valéria Lima publicou J.-B. Debret, historiador e pintor: a viagem pitoresca e histórica ao Brasil (1816-1839) (2007). Sobre esse tema, podemos ainda citar sua Tese de Doutoramento A viagem pitoresca e histórica de Debret: por uma nova leitura, defendida no Departamento de História do Instituto de Filosofia e Ciências Humanas, da Universidade Estadual de Campinas, em 2003, sob orientação do Prof. Robert Wayne A. Slenes.

${ }^{6}$ Ver Leenhardt, Jacques (2013).

7 Fazemos uso nesse artigo da edição publicada pela Livraria Martins em 1940 com a organização da coleção Biblioteca Histórica Brasileira, sob a direção de Rubens Borba de Moraes. Os três volumes originais foram alocados em dois tomos, com introdução de Rubens Borba de Moraes e tradução de Sérgio Milliet.

${ }^{8}$ Coube ao Instituto Histórico e Geográfico Brasileiro (IHGB) a recepção da obra. O primeiro volume dedicado aos indígenas é bem recebido pelos peritos desse instituto e passaria a fazer parte das coleções imperiais. O segundo volume, publicado pelos irmãos Firmin Didot (1835), dedicado ao Rio de Janeiro, destacando a presença dos escravos no cotidiano e no trabalho da cidade teria recepção diferente. Depois de algumas críticas quanto a imprecisões históricas do período de descobrimento do Brasil, a tese de Debret é refutada, ou seja, de que o Rio de Janeiro havia progredido pouco antes da chegada de d. João VI. Para Leenhardt, a desqualificação de Debret estaria relacionada à representação da escravidão pelo artista francês. Quando a comissão de análise da obra de Debret delibera, o Brasil havia condenado, sob pressão inglesa, o tráfico de escravos. No entanto, os navios negreiros continuavam a cruzar o Atlântico de forma clandestina. A partir de um parecer bastante suscinto, a comissão rejeita o segundo volume, com a observação de que não seria "nem oportuno nem político entrar no exame de algumas passagens sobre o caráter dos habitantes em geral, especialmente na página 18". Essa questão explicaria ainda os motivos pelos quais a obra de Debret foi esquecida por um século, até que o crítico Sérgio Milliet a traduzisse, tornando-se um dos documentos históricos e iconográfico mais importante sobre o Brasil. (Leenhardt, 2013, p. 518519)

${ }^{9}$ Consultamos para esse artigo a edição publicada pela Editora Itatiaia Limitada/Editora da Universidade de São Paulo. Edição completa, tiragem especial em fólio, com todas as ilustrações reproduzidas de um só lado da folha de 31,5 x 23,0 cm. Tradução Sérgio Milliet e Prefácio de Antonio Carlos Vilaça. Parte da Coleção Reconquista do Brasil (1998).

${ }^{10}$ Consultamos as edições publicada pela Editora da Universidade de Campinas: Burke (1993); Kant (1993) e a edição publicada pela Editora Forense Universitária: Kant (2002). 